\title{
Individual autonomy and state involvement in health care
}

Thomas Rice UCLA School of Public Heath, Los Angeles, USA

\begin{abstract}
This article examines the ethical basis for government involvement in health care. It first provides the case for individual autonomy, focusing on the

justifications-particularly ethical ones-for allowing individuals to make their own choices in health care, and to control more of their own resources in doing so. Next, it provides the opposite case-for abridging individual autonomy, and in particular, for redistributing resources from those who are well off to those who are not. The overriding reason for favouring the latter case, which trumps the notion of individual autonomy, is to ensure that individuals who are at a disadvantage have an equal probability of attaining good health.

(Fournal of Medical Ethics 2001;27:240-244)
\end{abstract}

Keywords: Distributive justice; ethics; government; health care

\section{Introduction}

For many decades and throughout the world, government has been deeply involved in the organisation, financing, and delivery of health care services. We usually take this strong involvement for granted, and sometimes even equate a country's health care system with the role taken by its government. This is unfortunate because the foundation and extent of government involvement are predicated on certain key ethical issues. One's take on the particulars of these issues drive one's views of when and how much government should intervene in the market-place.

Government has the power to influence any number of aspects of health care strongly. It can, for instance, control the number of providers as well as the kinds of services they deliver; set prices and the types (and even quality) of services that can be provided, particularly when public resources are involved; and have a strong influence on the introduction and diffusion of new products and technologies. One of the most important roles of government is the collecting of taxes, using the revenues to support further regulation of the sector, as well as to finance the distribution of services to those it deems most fit to receive them-most notably the poor, the elderly and veterans.

Having this power and using it ethically are, however, two different issues. What is the ethical basis for government intervention? Are there other strong reasons for government to intervene in the health care market-place? What implications does this have for the role that government does-and should-have in health care? This article considers these issues.

\section{The case for individual autonomy}

There are many reasons to believe that individuals should be able to make their own choices in health care. Moreover, there are reasons to think they should have control over (more of) their resources in order to make these choices rather than having them taxed away by government. This section focuses on three major advantages of consumer sovereignty in health care. These advantages are categorised below under the headings of economic efficiency, psychology, and fairness.

\section{ECONOMIC EFFICIENCY}

The central tenet of traditional economic theory is that consumers will be best off if they are allowed to make their own choices about the goods and services they consume. This belief is exemplified by the theory of revealed preference-which posits that allowing people to make their own economic choices will, in and of itself, make them best off. As developed by Paul Samuelson, ${ }^{1}$ people are assumed to prefer the bundle of goods that they purchase. If they choose one bundle over another, they have "revealed themselves" to prefer the former bundle.

The theory is unusually powerful because it does not require individuals to reflect on their underlying motivations. As Robert Sugden has written: "[The] most significant property of the revealed preference approach ... is that we do not need to enquire into the reasons why one thing is chosen rather than another. We do not look into the factors that go into the deliberation which leads to a choice; we look only at the results of that process ....".

The theory of revealed preferences relies on individuals' abilities to make utility-maximising choices. Going one step further, and assuming that social welfare is simply the sum of all individuals' welfare, we can conclude that allowing consumers to make their own choices will lead to the highest level of societal welfare. This is the precise argument made by proponents of competition: markets allow people to choose, resulting, in turn, in the best possible outcome for society. In other words, a society where all people make their own choices results in the highest level of satisfaction.

A related reason for encouraging choice is that the use of markets can lead to better value. Choice, 
of course, is a characteristic of a competitive market. Having a choice leads to a situation where firms strive to operate efficiently to keep prices low. And to the extent that the goods sold are not homogeneous, competition may also take place on the basis of quality. One should not underestimate the significance of this argument in favour of choice, since better value through lower prices and better quality has the potential to provide overwhelming advantages to consumers.

\section{PSYCHOLOGY}

The second reason for believing that consumers should have autonomy-in health care as well as throughout the economy-is more psychological in nature: individuals are likely to get more satisfaction out of the goods and services they purchase if they choose them. It is plausible that individuals would prefer the particular goods that they picked out of a set of alternatives, rather than having had these goods assigned to them by someone else. This can be clarified by the following thought experiment. Your employer knows that you need a new car to get to work, knows that you have a certain budget, and picks out for you a particular make, model, and colour, withholding its cost from your pay-check. Compare that to a situation where you pick out your own car. Even if it turns out that you would have picked exactly the same car, the latter situation would satisfy more people because they know it was their choice. When the particular car is assigned by an outside agent, you may be concerned that you might have picked differently if given the choice. Consequently, your satisfaction with the decision will be lower. Some might argue that this would be even more true in health care, where consumer decisions (such as what doctor to see) are very personal, individualistic, and can be of considerable import.

\section{FAIRNESS}

An argument can be made that it is unfair to tax away an individual's resources to spend either on other people, or alternatively, on health care resources that the person may not have chosen. Perhaps the main proponent of this philosophy is Robert Nozick, ${ }^{3}$ partly in response to John Rawls.

\section{Rawls's theory}

Briefly, Rawls's theory provides an alternative to utilitarian philosophy. In the latter, society's goal is to maximise collective utility. In contrast, Rawls invokes the notion of fairness to determine how society's resources are distributed. To determine what is fair, he invokes a concept called the "original position", in which people choose the principles of a just society from a position where, "no one knows his place in society, his class position or social status, nor does any one know his fortune in the distribution of natural assets and abilities, his intelligence, strength, and the like" ${ }^{5}$ Rawls calls this lack of information about one's own talents and standing, a "veil of ignorance". His goal is to determine what system of justice rational, self-oriented people would choose when placed in the original position.

Rawls posits that people in the original position would accept the proposition that primary goods (which he defines as "rights and liberties, powers and opportunities, income and wealth") "be distributed equally unless an unequal distribution of any, or all, of these values is to everyone's advantage. Injustice, then, is simply inequalities that are not to the benefit of everyone". ${ }^{6}$

The upshot is that society is better off only when it makes its least well-off people better off. In other words, society's resources should be devoted to increasing the primary goods possessed by the most disadvantaged people. The only time that resources will go to the group that does not occupy the bottom rung is when, by so doing, benefits will trickle down to the most disadvantaged group. The overriding implication is that society should engage in far more redistribution than it does currently. This is because resource distribution is quite skewed and, moreover, because much if not most of current redistributive programmes are not targeted solely at those who are worst off in society.

Why would people who are placed in the original position decide on this particular conception of justice? Rawls answers: "Since it is not reasonable for [a person] to expect more than an equal share in the division of social goods, and since it is not rational for him to agree to less, the sensible thing for him to do is to acknowledge as the first principle of justice one requiring an equal distribution. Indeed, this principle is so obvious that we would expect it to occur to anyone immediately."”

Some analysts believe Rawls overlooked a key primary good-access to good health care. According to Ronald Green: "Access to health care is not only a social primary good, but possibly one of the most important such goods [because] disease and ill health interfere with our happiness and undermine our self-confidence and self-respect":

Although Rawls's theory is often praised even by those who have criticised it, a number of objections have been raised. One is that people would not choose to redistribute primary goods only to those who are worst off . ${ }^{9}$ Another is that, when asked, people seem to choose to maximise average income subject to some minimum floor rather than Rawls's solution. ${ }^{10} \mathrm{~A}$ third objection is that there is little place in Rawls's theory for rewarding motivation or hard work, which has ethical implications in itself and raises major issues concerning the efficiency of such a system. ${ }^{11}$

\section{Nozick's view of fairness}

A much more fundamental criticism of Rawls, called "entitlement theory," has been developed by Robert Nozick. Nozick begins by positing a conception of a just role of government, concluding that this would be a "minimalist state" in which government's role is limited to such things as mutual protection and enforcement of contracts: 
"any state more extensive violates people's rights". ${ }^{12}$ He concludes that: "The minimalist state treats us as inviolate individuals, who may not be used in certain ways by others as means or tools or instruments or resources; it treats us as persons having individual rights with the dignity this constitutes. Treating us with respect by respecting our rights, it allows us ... to choose our life and to realize our ends and our conception of ourselves, insofar as we can, aided by the voluntary cooperation of other individuals possessing the same dignity. How dare any state or group of individuals do more. Or less." ${ }^{13}$

There are two main aspects to justice under Nozick's entitlement theory. The first is the "principle of justice in acquisition of holdings," which pertains to how a person originally attained a resource, and the second is the "principle of justice in transfer of holdings," which concerns resources that they subsequently obtain from others. Essentially, what Nozick says is that if a person originally obtained a resource without violating anyone else's rights, or from another person voluntarily, then he or she is entitled to it.

Unlike Rawls, Nozick believes that people should be able to enjoy the full fruits of any natural advantage they enjoy. If, say, a person is born smart and, as a result, becomes rich, that individual should keep all of his or her wealth as long as the person violates nobody else's rights. Rawls, however, would likely contend that being born smart is a lucky advantage that does not make the person deserving of additional primary resources. Nozick interprets Rawls's view as saying that "everyone has some entitlement or claim on the totality of natural assets ... with no one having differential claims. The distribution of natural abilities is viewed as a 'collective asset'". ${ }^{14}$

At one point in his book, Nozick uses health care as an example. He presents and then refutes an argument made by Bernard Williams, ${ }^{15}$ who claimed that societal resources should be redistributed to those in poor health who cannot afford necessary medical care. Nozick counters that Williams "ignores the question of where the things or actions to be allocated and distributed come from. Consequently, he does not consider whether they come already tied to people who have entitlements over them (surely the case for service activities, which are people's actions), people who therefore may decide for themselves to whom they will give the thing and on what grounds." 16

Many objections can be raised about Nozick's conception of justice. Indirectly, at least, the remainder of this article notes several, in its attemp to justify government involvement in health care. From a philosophical standpoint, the major objection is that people who start at a disadvantage are likely to remain at one. Recall that Nozick says that holdings that were acquired fairly must not be taken involuntarily from an individual. Who is to say what is a fair way of acquiring resources? And how can it be called fair if some people are born in such a disadvantaged position that they effectively have no way to overcome it? Even Nozick admits that he is "as well aware as anyone of how sketchy [his] discussion of the entitlement conception of justice in holdings has been". ${ }^{17} \mathrm{~A}$ less charitable view is that it is a philosophy espousing the rule of "finders keepers". ${ }^{18} 10$

\section{The case for abridging individual autonomy}

The case for abridging individual autonomy through government involvement in health care delivery and financing can be based on both fairness and efficiency considerations, each of which is discussed separately, below. More emphasis is given to equity since our concerns here are primarily ethical ones.

FAIRNESS

Why do many philosophers believe that people should not be granted full property rights over the resources they have inherited and/or earned. Rawls states that: "No one deserves his greater natural capacity nor merits a more favorable starting place in society", ${ }^{20}$ and even among economists there are many who agree. Kenneth Arrow, in writing about Rawls's book, notes that under the theory: "[E]ven natural advantages, superiorities of intelligence or strength, do not in themselves create any claims to greater rewards... . Personally, I share fully this value judgment ... . But a contradictory positionthat an individual is entitled to what he creates-is widely and unreflectively held; when teaching elementary economics, I have had considerable difficulty in persuading the students that this productivity principle is not completely self-evident."21

Why might one believe-in contrast to Nozick as well as students in elementary economics coursesthat a person is not fully entitled to the wealth he or she has inherited or accumulated? As a starting point to addressing this question, consider the literature on moral philosophy. Much of it concludes that in a fair society, something must be equalised. A reason is provided by Amartya Sen: "It may be useful to ask why it is that so many altogether different substantive theories of the ethics of social arrangements have the common feature of demanding equality of something-something important. It is, I believe, arguable that to have any kind of plausibility, ethical reasoning on social matters must involve elementary equal consideration for all at some level that is seen as critical. The absence of such equality would make a theory arbitrarily discriminating and hard to defend. A theory must accept-indeed demand-inequality in terms of many variables, but in defending those inequalities it would be hard to duck the need to relate them, ultimately, to equal consideration for all in some adequately substantial way."22

Sen notes that even Nozick's philosophy does call for the equalisation of something-libertarian rights. Unfortunately, deciding that something ought to be equalised does not tell us what that should be. To consider this, we must first distinguish between two very different but similarly-sounding terms: "equality" and "equity." The former means equal shares 
of something, but the latter means a "fair" or "just" distribution-which may not mean equal shares.

The distinction between equality and equity can be understood by examining the two economic terms: horizontal equity and vertical equity. Horizontal equity means that two otherwise similar people are treated the same with respect to a particular thing-what we are referring to here as equality. But vertical equity is much different; it is, according to Gavin Mooney, "the unequal but equitable treatment of unequals". ${ }^{23}$ One might, for instance, establish a lower tax rate for the poor than the rich in the name of equity.

What, then, should be equalised? One line of thought, advocated by Ronald Dworkin, ${ }^{24}$ is that people's "resources" should be equalised-a philosophy that would appear to be not terribly different from Rawls's equalisation of primary goods Another, put forward by John Roemer, ${ }^{11}$ is that people's "opportunity" should be equalised. Under this concept, individuals should be responsible for their own actions after they are placed on a level playing-field. Roemer distinguishes between factors that are under a person's control and those that are beyond it. For example, let's say we want to choose which people to compensate when they contract lung cancer so they can pay for their medical care. The first step is to make a list of factors over which people have little control such as age, ethnicity, gender and occupation. We then examine the smoking behaviour of these population groupings. Suppose that the average 60-year-old, male, black steelworker smokes for 30 years, and the average 60-year-old, female, white college professor smokes for eight years. Then, if we are faced by compensation claims from a steelworker who has contracted lung cancer who smoked for 20 years, and a professor who smoked for 15 , the steelworker would receive more compensation-because his behaviour was more responsible given the circumstances over which he had little or no control. Stated differently, had the steelworker had the same opportunity to become educated about smoking behaviour as the white college professor, he likely would have smoked less than her. When we put them on a level playing-field by comparing their behaviours with those of others in similar circumstances, the steelworker showed more responsible behaviour and, if resources are being allocated accordingly, should receive a bigger share.

A final candidate for equalisation, advocated by Sen, is the equalisation of capabilities, which "reflect a person's freedom to choose between alternative lives". ${ }^{25}$ The purpose is to give people the ability to achieve the things they want. It is designed to focus not on resources themselves, but what resources can do for a person.

Equalising capabilities differs from Rawls's theory and from equalising resources, in that under those systems people are given physical resources but not necessarily the ability to use them for their own means. It also differs from equality of opportunity because giving someone the opportunity does not necessarily mean they will be able to utilise that opportunity effectively. Equality of capabilities might mean that more resources would be given to a disabled person because that person would need more to reach their goals in life.

Whether one believes in equalising Rawlsian primary goods, resources, opportunity, capabilities, or some other construct, there is a common policy implication: to ensure that individuals who are at a disadvantage have an equal probability of attaining good health, it is necessary to redistribute resources from those who have been more fortunate. This, in a nutshell, is the ethical argument for government intervention in the health care market.

\section{EFFICIENCY}

The focus up till now has been on ethical considerations. Here we briefly mention the other reason that government might intervene in the market-to improve economic efficiency. Indeed, many if not most of the reasons that government intervenes in health care have nothing to do with fairness, but rather with economic efficiency.

There are a number of "classic reasons" for government intervention in health care. Some goods and services might be public goods, where the good or service in question can be consumed by numerous people at once without detracting from each other's enjoyment of it, and where it is difficult to exclude people from using it, even if they do not pay. (An example in health care might be television announcements providing the public with useful medical information.) Not surprisingly, these are typically underproduced by competitive markets.

Other goods have "externalities" associated with them. When there are positive externalities, a person's or firm's actions have benefits that accrue to those who are not involved in the transaction (for example, immunisations benefit others). In the case of negative externalities, transactions have a negative effect on others (for example, smoking). A free market tends to underproduce goods and services that have positive externalities, and overproduces those with negative externalities. Government intervention of some sort may rectify the situation, and may be the least costly way of doing so.

A third example are goods that are characterised by "increasing returns to scale"-basically, when average costs decline as the scale of production increases. This usually occurs when a very large capital investment is necessary and it is uneconomical for more than one firm to be in a particular market. State-of-the-art teaching hospitals are sometimes thought of as such an example; without government subsidies they might never be profitable.

The above examples are typical justifications for government intervention in many markets, not just health care. But health care has its own peculiarities, which also may necessitate government involvement to improve efficiency. I have written a book on these issues and will not repeat them here. ${ }^{26}$ Some examples include:

- Having the government provide objective information about health plan, hospital or physician 
quality because consumers would find it difficult to make a utility-maximising choice without it; markets tend to underproduce public goods such as information.

- Controlling the diffusion of medical technologies because they are being overused, thus raising health care cost with little to show in the way of marginal benefits.

- Regulating the enrolment practices of insurers, who otherwise might avoid particular patients or small employers who have a history of illness. This is not just an issue of equity; insurance markets are inefficient if they are not available to a segment of the population who desire coverage.

When using efficiency criteria to justify government intervention, it is necessary to understand that governmental actions will help some individuals and firms and hurt others. Put differently, government actions will nearly always be viewed as unfair by some. Ideally, one would hope that government would act when there will be an overall improvement in the workings of society or the economy One might also hope that providing health care coverage or services to those who would otherwise be unable to afford them would benefit those who get satisfaction from knowing they live in a more compassionate society (which an economist would refer to as a "positive externality of consumption"). But whether these things are sufficient to make up for the losses suffered by some is an ethical issue that must always be faced.

\section{Conclusion}

A number of reasons-economic, psychological, and ethical-can be given for granting individuals autonomy over the choices they make in health care. Moreover, similar arguments can be made for people to have more control over their economic resources rather than taxing them away by government. There are, nevertheless, even more compelling reasons for government to become actively involved in health care. This article focused on ethical reasons, although there are efficiency reasons for doing so as well. The main ethical reason for government involvement is that individuals should not be penalised-through poorer access to health care services and/or poorer health-because of economic or social circumstances which are beyond their control. Redistributing resources is necessary if they are to have the same opportunity to enjoy good health as others.

Thomas Rice, PhD, is Professor in the Department of Health Services, UCLA School of Public Health, Los Angeles, USA.

\section{References}

1 Samuelson PA. A note on the pure theory of consumer behaviour. Economica 1938;5:61-71.

2 Sugden R. Welfare, resources, and capabilities: a review of inequality reexamined by Amartya Sen. Fournal of Economic inequality reexamined by Am

3 Nozick R. Anarchy, state, and utopia. New York, NY: Basic Books, 1974

4 Rawls J. A theory of justice. Cambridge, MA: The Belknap Press of Harvard University, 1971.

5 See reference $4: 12$.

6 See reference 4: 62 .

7 See reference 4: 150-1.

8 Green RM. Health care and justice in contract theory perspective. In: Veatch RM, Branson R, eds. Ethics and health policy. Cambridge, MA: Ballinger, 1976.

9 Sen A. Choice, welfare and measurement. Oxford: Blackwell, 1982.

10 Miller D. Distributive justice. Ethics 1992;102:555-93.

11 Roemer J. Equality and responsibility. Boston Review 1995;20: 3-7.

12 See reference 3: 149.

13 See reference 3: $334-5$

13 See reference 3: $334-5$

15 Williams B. The idea of equality. In: Laslett P, Runciman WG, eds. Philosophy, politics, and society [2nd ser ed]. Oxford: Blackwell, 1962: 235

16 See reference 3: 235

17 See reference 3: 230.

18 Elster J. Local justice: how institutions allocate scarce goods and necessary burdens. New York, NY: Russell Sage Foundation, 1992.

19 Stone DA. Policy paradox: the art of political decision-making. New York, NY: Norton, 1996.

20 See reference 4: 102.

21 Arrow KJ. Some ordinalist-utilitarian notes of Rawls's theory of justice. Social choice and justice: collected papers of Kenneth $\mathcal{f}$ Arrow. Cambridge, MA: Belknap Press of Harvard University Press, 1983.

22 Sen A. Inequality revisited. Cambridge, MA: Harvard University Press, 1992: 17.

23 Mooney G. And now for vertical equity? Some concerns arising from Aboriginal health in Australia. Health Economics 1996;5: 99-103.

24 Dworkin R. What is equality? Part 2: equality of resources. Philosophy \& Public Affairs 1981;10:283-345.

25 See reference 22: 83 .

26 Rice T. The economics of health reconsidered. Chicago, IL: Health Administration Press, 1998 